Article

\title{
Efficient One-Pot Synthesis of a Hexamethylenetetramine-Doped Cu-BDC Metal-Organic Framework with Enhanced $\mathrm{CO}_{2}$ Adsorption
}

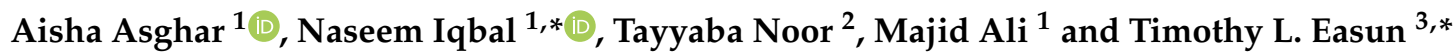 \\ 1 U.S Pakistan Centre for Advanced Studies in Energy, National University of Sciences and Technology, H-12, \\ Islamabad 44000, Pakistan \\ 2 School of Chemical and Materials Engineering, National University of Sciences and Technology, H-12, \\ Islamabad 44000, Pakistan \\ 3 School of Chemistry, Cardiff University, Main Building, Park Place, Cardiff CF10 3AT, UK \\ * Correspondence: naseem@uspcase.nust.edu.pk (N.I.); easuntl@cardiff.ac.uk (T.L.E.)
}

Received: 14 May 2019; Accepted: 30 June 2019; Published: 24 July 2019

\begin{abstract}
Herein we report a facile, efficient, low cost, and easily scalable route for an amine-functionalized MOF (metal organic framework) synthesis. Cu-BDC $\supset$ HMTA (HMTA = hexamethylenetetramine) has high nitrogen content and improved thermal stability when compared with the previously reported and well-studied parent Cu-BDC MOF (BDC $=1$,4-benzenedicarboxylate). Cu-BDC $\supset$ HMTA was obtained via the same synthetic method, but with the addition of HMTA in a single step synthesis. Thermogravimetric studies reveal that $\mathrm{Cu}$-BDC $\supset$ HMTA is more thermally stable than $\mathrm{Cu}$-BDC MOF. $\mathrm{Cu}$-BDC $\supset$ HMTA exhibited a $\mathrm{CO}_{2}$ uptake of $21.2 \mathrm{wt} \%$ at $273 \mathrm{~K}$ and $1 \mathrm{bar}$, which compares favorably to other nitrogen-containing MOF materials.
\end{abstract}

Keywords: energy efficiency; functional metal organic frameworks; $\mathrm{Cu}-\mathrm{BDC} ; \mathrm{HMTA} ; \mathrm{CO}_{2}$ adsorption

\section{Introduction}

The world is currently facing the urgent and demanding challenges of saving and utilizing energy as efficiently as possible. Ever increasing carbon dioxide levels in the atmosphere are a serious threat to the environment [1]. Various carbon capture techniques have been explored to mitigate carbon dioxide levels in the atmosphere, including point source $\mathrm{CO}_{2}$ capture using advanced materials [2]. Metal-organic frameworks (MOFs) are an advanced class of microporous and often crystalline nanomaterials comprised of metal coordination sites bridged by organic linkers $[3,4]$. The resulting organic/inorganic hybrid 3-D networks that form often contain well-defined porosity, high surface area, and tunable chemical functionalities with potential for versatile applications in catalysis [5,6], separations [7], and gas storage [8]. With respect to the last of these, many studies have investigated the capture of carbon dioxide gas. Amine sites have an affinity towards carbon dioxide, are known to be highly effective at enhancing $\mathrm{CO}_{2}$ adsorption, and are amenable to use under dry or humid conditions. [9]. In this paper, we describe the synthesis, characterization and $\mathrm{CO}_{2}$ sorption of a hexamethylenetetramine-doped metal-organic framework. This study is an effort to incorporate hexamethylenetetramine within a Cu-BDC (BDC = 1,4-benzenedicarboxylate) framework, using an in-situ modification during synthesis, and to study the effect on carbon dioxide gas sorption capacity. Herein, we report a very straightforward method for modification of already reported $\mathrm{Cu}-\mathrm{BDC}$ [10]. The strategy has several advantages. First, the entire synthetic procedure is quite simple. Second, this method is efficient, with the potential for high-yields, and hexamethylenetetramine is 
a low-cost chemical (£15.68/kg [11]). Third, a high nitrogen content can be achieved in the resulting Cu-BDCつHMTA material.

\section{Materials and Methods}

All the chemicals were purchased from Sigma Aldrich/Merck (St. Louis, MO, USA) and used as received.

\subsection{Synthesis}

To prepare Cu-BDC $\supset$ HMTA, equimolar quantities (1:1:1) of $\mathrm{Cu}\left(\mathrm{NO}_{3}\right)_{2} \cdot 6 \mathrm{H}_{2} \mathrm{O}(296 \mathrm{mg}, 1 \mathrm{mmol})$, terephthalic acid (166 mg, $1 \mathrm{mmol})$ and hexamethylenetetramine $(140 \mathrm{mg}, 1 \mathrm{mmol})$ were dissolved in $10 \mathrm{~mL}$ DMF in a $50 \mathrm{~mL}$ beaker. The contents were ultrasonicated at $25^{\circ} \mathrm{C}$ for $30 \mathrm{~min}$, and then the solution was transferred to a $23 \mathrm{~mL}$ Teflon vial in a steel Parr vessel. The Parr vessel was sealed and heated in an oven at $110^{\circ} \mathrm{C}$ for $24 \mathrm{~h}$ to yield greenish-blue crystals. The reaction mixture was decanted, the product washed three times with DMF $(5 \mathrm{~mL})$, and then three times with THF $(5 \mathrm{~mL})$. This yielded blue crystals. The sample was activated in a vacuum oven at $130{ }^{\circ} \mathrm{C}$ for $12 \mathrm{~h}$ before further analysis. The same synthesis strategy was used for obtaining $\mathrm{Cu}-\mathrm{BDC}$ MOF, without the addition of HMTA [10]. This yielded blue crystals. A schematic reaction scheme for $\mathrm{Cu}$-BDC $\supset$ HMTA synthesis is shown in Figure 1.

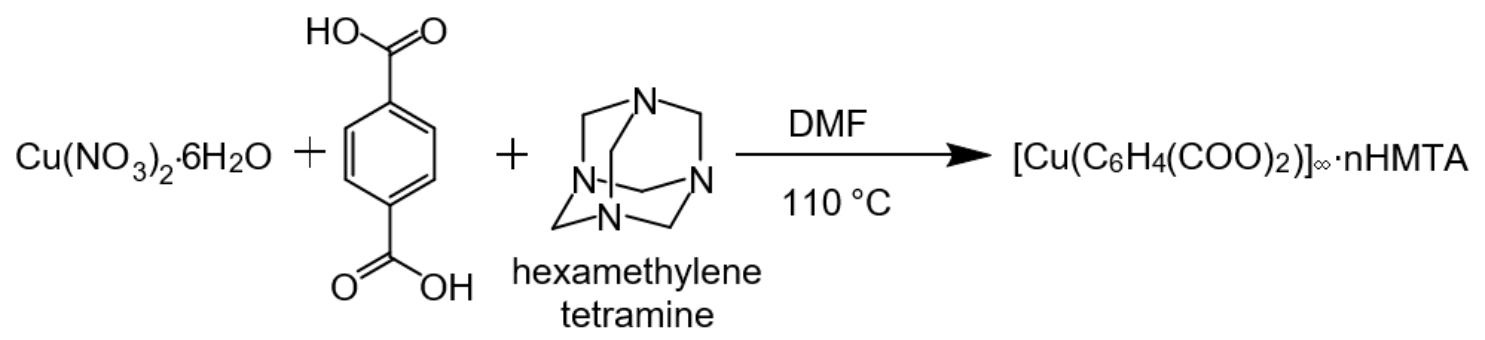

Figure 1. Reaction scheme for $\mathrm{Cu}-\mathrm{BDC} \supset \mathrm{HMTA}$ synthesis.

\subsection{Characterization}

Powder X-ray diffraction (PXRD) patterns were collected on an X'PertPro Panalytical Chiller 59 diffractometer (Malvern, UK) using copper K $\alpha(1.54 \AA)$ radiation. Diffraction patterns were recorded in the $2 \theta$ range, from 4.00 to 39.09 degrees, with a $2 \theta$ step size of 0.017 , and a scan per step of

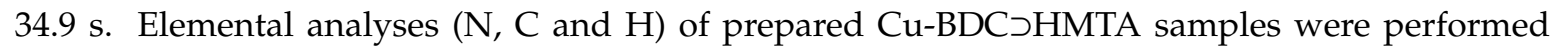
to confirm presence of amine in the prepared material, using a FlashSmart NC ORG elemental analyzer (Oxford, UK). Thermogravimetic analyses (TGA) were performed using a Perkin Elmer Pyris 1 thermo-gravimetric analyzer (Champaign, IL, USA). The temperature was increased from $25^{\circ} \mathrm{C}$ to $700{ }^{\circ} \mathrm{C}$ at a heating rate of $5^{\circ} \mathrm{C} \mathrm{min}^{-1}$ under a flow of air $\left(20 \mathrm{~mL} \mathrm{~min}^{-1}\right)$. SEM images were collected using TESCAN/VEGA-3 equipment (Brno, Czech Republic). A SHIMADZU IR Affinitt-1S spectrometer (Kyoto, Japan) was used to obtain IR spectra.

Prior to $\mathrm{CO}_{2}$ sorption studies, the samples were degassed at $130^{\circ} \mathrm{C}$ for $10 \mathrm{~h}$ and then back-filled with helium gas. $\mathrm{CO}_{2}$ adsorption experiments were performed on a Quantachrome Isorb-HP100 volumetric type sorption analyzer (Boynton Beach, FL, USA). The sample was tested for adsorption at two different temperatures: $0{ }^{\circ} \mathrm{C}$ and $25^{\circ} \mathrm{C}$, at pressures from 1-14 bar. $\mathrm{N}_{2}$ adsorption studies of the MOF were conducted to analyze surface area and pore volume using a Quantachrome Nova $2200 \mathrm{e}$ at $-196{ }^{\circ} \mathrm{C}$ at a relative pressure of $\mathrm{P} / \mathrm{P}^{0}=0.1-1.0$ and prior to the measurement, samples were degassed at $160^{\circ} \mathrm{C}$ under vacuum for $11 \mathrm{~h}$. 


\section{Results and Discussion}

\subsection{PXRD Patterns of $C u-B D C$ and $C u-B D C \supset H M T A$}

Powder X-ray diffraction patterns, for products of the synthesis of Cu-BDC and Cu-BDCつHMTA, were collected and are shown in Figure 2. Both synthesized materials show sharp diffraction peaks indicating predominantly crystalline material. The peak positions are in good agreement with the PXRD of Cu-BDC previously reported by Carson et al. in 2009, indicating successful synthesis of the Cu-BDC [10]. There are several additional peaks in the PXRD pattern of Cu-BDCつHMTA, most notably at $2 \theta=8.31^{\circ}$. These cannot be ascribed to a simple mechanical mixture of Cu-BDC and HMTA as, firstly, HMTA is soluble in the organic solvents used to wash the reaction product, which makes this option unlikely. Secondly, the increased $\mathrm{CO}_{2}$ sorption observed in the Cu-BDCつHMTA product (described below) is not consistent with a simple physical mixture of Cu-BDC and HMTA, which we would anticipate having a lower gas uptake than the pure Cu-BDC alone. Thirdly, and most conclusively, the powder XRD pattern of pure HMTA is shown in Figure 2, and no HMTA peaks correspond to the new peaks observed in $\mathrm{Cu}$-BDC $\supset$ HMTA. We tentatively ascribe the additional peaks to well-ordered HMTA molecules binding to the axial copper sites in the framework. Inspecting the (previously reported) Cu-BDC crystal structure [10] shows that the 2D layers pack with significantly offset paddlewheels from one layer to the next, with copper centers separated by $6.331 \AA(\mathrm{Cu}-\mathrm{Cu}$ distance). Looking approximately along the $\mathrm{Cu}-\mathrm{Cu}$ axis, although still with some notable offset, the next available paddlewheel is $9.068 \AA(\mathrm{Cu}-\mathrm{Cu}$ distance) away. HMTA has four potentially coordinating nitrogen atoms separated by $\sim 2.47 \AA(\mathrm{N}-\mathrm{N})$ across a tricyclic, adamantane-like cage [12]. There are examples of HMTA bridging copper nodes in a metal-organic framework, but these typically involve much shorter $\mathrm{Cu}-\mathrm{Cu}$ distances (5.761 $\AA$ in the cited example) with an angle between the Cu-N bonds of adjacent centres across the HMTA of $\sim 108^{\circ}$, which is not possible in our Cu-BDCDHMTA framework [12]. Further indirect evidence for bonding of HMTA to the framework is that it is not readily removed by simple washing with organic solvents. It has not been possible at this stage to synthesize crystals of Cu-BDCつHMTA of sufficient size and quality to obtain the single-crystal $\mathrm{X}$-ray structure.

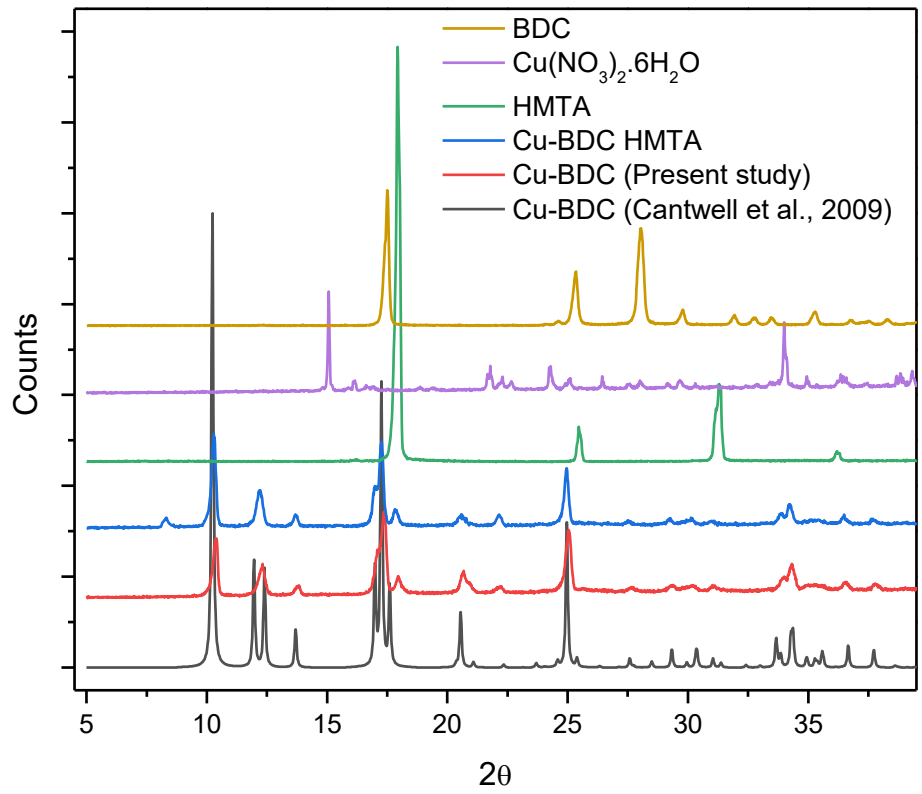

Figure 2. PXRD patterns for Cu-BDC (black, reported by Carson et al., 2009), Cu-BDC (red, synthesized herein), $\mathrm{Cu}-\mathrm{BDC} \supset \mathrm{HMTA}$ (blue), HMTA (green), $\mathrm{Cu}\left(\mathrm{NO}_{3}\right)_{2} \cdot 6 \mathrm{H}_{2} \mathrm{O}$ (lilac) and the $\mathrm{H}_{2} \mathrm{BDC}$ linker (dark yellow). 


\subsection{FTIR of $C u-B D C$ and $C u-B D C \supset H M T A$}

Fourier transform infrared spectra (FTIR) collected for prepared materials confirm the presence of representative functional groups indicative of $\mathrm{Cu}-\mathrm{BDC} \mathrm{MOF}$ formation (Figure 3). Sharp peaks representative of symmetric and asymmetric stretching of carboxylates bonded to $\mathrm{Cu}$ are observed at $1521 \mathrm{~cm}^{-1}$ and $1362 \mathrm{~cm}^{-1}$ in the Cu-BDC sample [10]. Both materials show the presence of what is likely to be water (even after vacuum-oven drying the samples) in the form of a broad peak centered around $3400 \mathrm{~cm}^{-1}$, which is much more evident in the $\mathrm{Cu}-\mathrm{BDC}$ sample than in the $\mathrm{Cu}-\mathrm{BDC} \supset \mathrm{HMTA}$ material and is likely due to the rapid uptake of atmospheric water when performing the measurement in air. The relatively reduced water content in the $\mathrm{Cu}$-BDC $\supset$ HMTA sample may indicate slower water adsorption as a result of pore-blocking by adsorbed HMTA and, in agreement with the binding of HMTA to copper nodes proposed above, the occupation of axial sites on the copper paddlewheels by HMTA which otherwise could rapidly adsorb water. In addition to peaks coincident with those of $\mathrm{Cu}$-BDC MOF, the $\mathrm{Cu}$-BDC $\supset$ HMTA sample illustrates some new features. A characteristic peak for amine-containing functional groups is observed at $1089 \mathrm{~cm}^{-1}$, consistent with C-N bond stretching $[13,14]$. Peaks at 2915 and $2845 \mathrm{~cm}^{-1}$ can be ascribed to stretching vibrations of $\mathrm{C}-\mathrm{H}$ bonds introduced by the incorporation of HMTA [14,15].

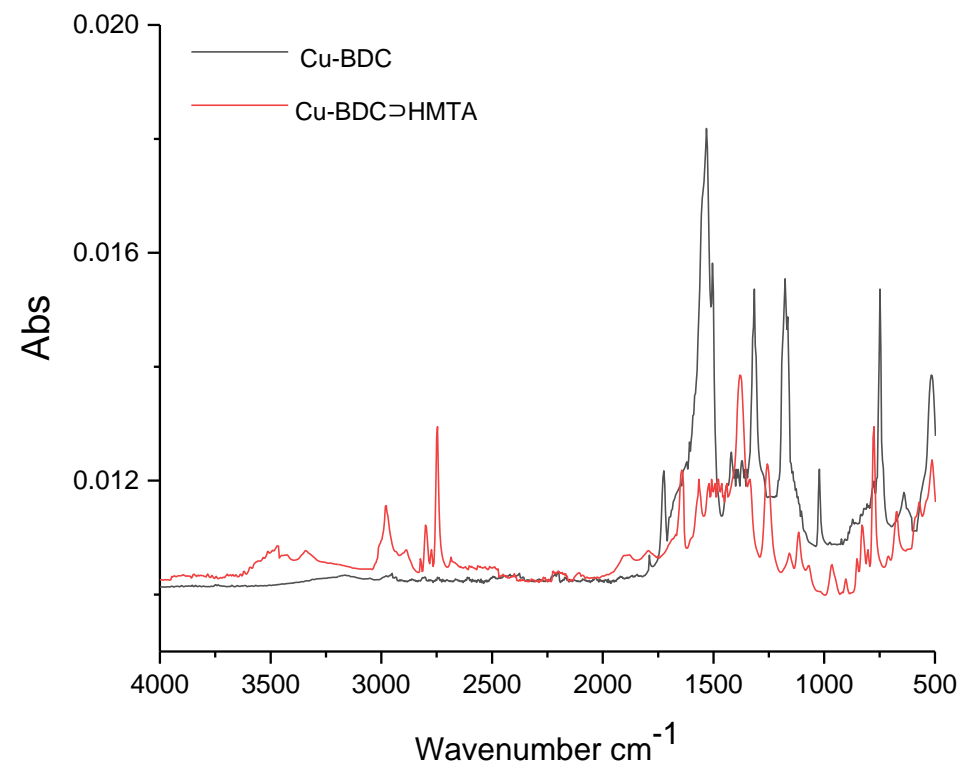

Figure 3. FTIR spectra for $\mathrm{Cu}-\mathrm{BDC}$ and $\mathrm{Cu}-\mathrm{BDC} \supset \mathrm{HMTA}$.

\subsection{Thermal Stability of $C u-B D C$ and $C u-B D C \supset H M T A$}

The two materials were studied by TGA and the results are shown in Figure 4. For both MOFs there is less than $2 \%$ weight loss observed below $150{ }^{\circ} \mathrm{C}$, indicating the pre-treatment has removed the majority of the residual solvent, and there is only minimal adsorbed moisture. The small weight loss in Cu-BDC between $170^{\circ} \mathrm{C}$ and $320^{\circ} \mathrm{C}$ (approx. $8 \%$ ) is consistent with loss of surface adsorbed DMF [13]. For Cu-BDC, decomposition of the benzene dicarboxylate starts at about $375^{\circ} \mathrm{C}$, above which temperature there is rapid degradation to the metal oxide. Notably, there is multi-step degradation of $\mathrm{Cu}$-BDC $\supset$ HMTA, with mass losses from $\sim 250^{\circ} \mathrm{C}$ and $425^{\circ} \mathrm{C}$ consistent with HMTA sublimation and thermal degradation, respectively. In Cu-BDC $\supset$ HMTA, linker degradation appears to be overlapped with HMTA degradation. No further weight loss was observed above $450{ }^{\circ} \mathrm{C}$ for $\mathrm{Cu}-\mathrm{BDC} \mathrm{MOF}$, and above $550{ }^{\circ} \mathrm{C}$ for $\mathrm{Cu}$-BDC $\supset$ HMTA. The $\mathrm{Cu}$-BDC thermal degradation results in $25 \%$ metal oxide, and $74 \%$ linker + DMF in the initial mass, consistent with the expected metal:linker:DMF ratio of 1:1:1. The relative proportions of $\mathrm{Cu}$-BDC $\supset$ HMTA components cannot reliably be extracted from these data due to the difficulty disentangling the overlapping mass losses of HMTA and linker in this experiment. 


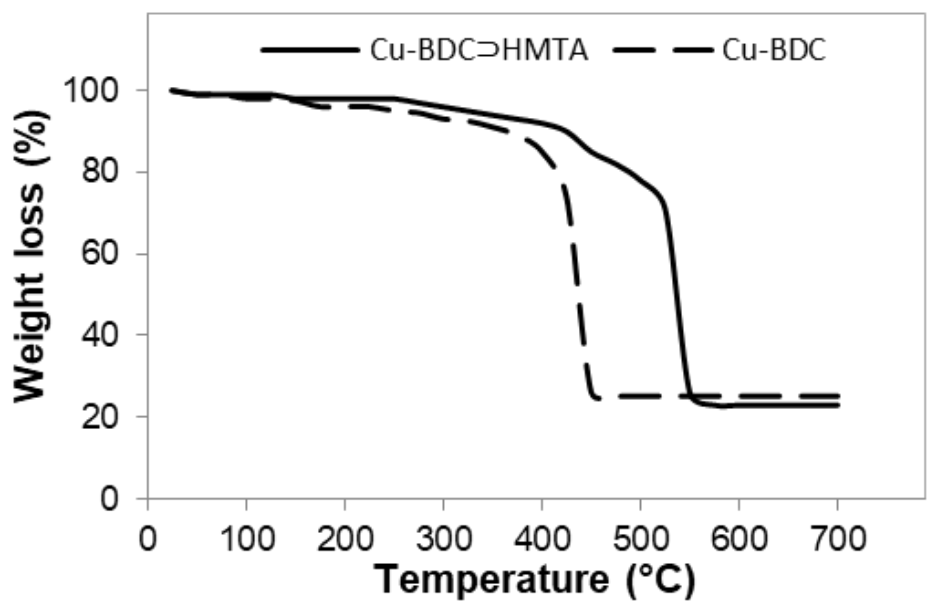

Figure 4. TGA of $\mathrm{Cu}-\mathrm{BDC} \mathrm{MOF}$ (dashed line) and Cu-BDCつHMTA (solid line).

\subsection{Elemental Composition of $C u-B D C$ and $C u-B D C \supset H M T A$}

To confirm the chemical composition of both samples, elemental analysis and EDS were performed (Table 1). The empirical formulae calculated on the basis of EDS, and elemental analysis for Cu-BDC, and $\mathrm{Cu}-\mathrm{BDC} \supset \mathrm{HMTA}$ are: $\mathrm{C}_{11} \mathrm{H}_{11} \mathrm{CuNO}_{5}$ and $\mathrm{C}_{14} \mathrm{H}_{16} \mathrm{CuN}_{4} \mathrm{O}_{4}$, respectively. This is consistent with metal: linker: \{DMF or HMTA, respectively\} molar ratios of 1:1:1, and in line with each of the copper axial sites being occupied by HMTA in Cu-BDC $\supset$ HMTA.

Table 1. Elemental composition of $\mathrm{Cu}-\mathrm{BDC}$ and $\mathrm{Cu}-\mathrm{BDC} \supset \mathrm{HMTA}$.

\begin{tabular}{cccccccc}
\hline Elemental Composition & \multicolumn{2}{c}{ Calculated by Elemental Analyzer } & \multicolumn{4}{c}{ Calculated by EDS } \\
\hline MOF Sample & $\mathbf{C}$ & $\mathbf{H}$ & $\mathbf{N}$ & $\mathbf{C}$ & $\mathbf{O}$ & $\mathbf{N}$ & $\mathbf{C u}$ \\
\hline \multirow{2}{*}{$\mathrm{Cu}-\mathrm{BDC}$} & 44.03 & 3.64 & 4.63 & 45.94 & 27.27 & 5.70 & 21.09 \\
& $(44.07)$ & $(3.69)$ & $(4.67)$ & $(44.0)$ & $(26.62)$ & $(4.67)$ & $(21.13)$ \\
\hline \multirow{2}{*}{ Cu-BDCつHMTA } & 45.80 & 4.4 & 15.30 & 47.81 & 18.59 & 16.30 & 17.30 \\
& $(45.77)$ & $(4.39)$ & $(15.26)$ & $(45.77)$ & $(17.41)$ & $(15.26)$ & $(17.27)$ \\
\hline
\end{tabular}

Note: Theoretical values in brackets and calculated values outside brackets.

\subsection{Morphology of $\mathrm{Cu}-\mathrm{BDC}$ and $\mathrm{Cu}-\mathrm{BDC} \supset H M T A$}

Scanning electron microscopy images of the prepared samples are shown in Figure 5. The $\mathrm{Cu}-\mathrm{BDC}$ crystallites have a plate like structure, while $\mathrm{Cu}$-BDC $\supset$ HMTA shows a more regular flat rod-like structure.
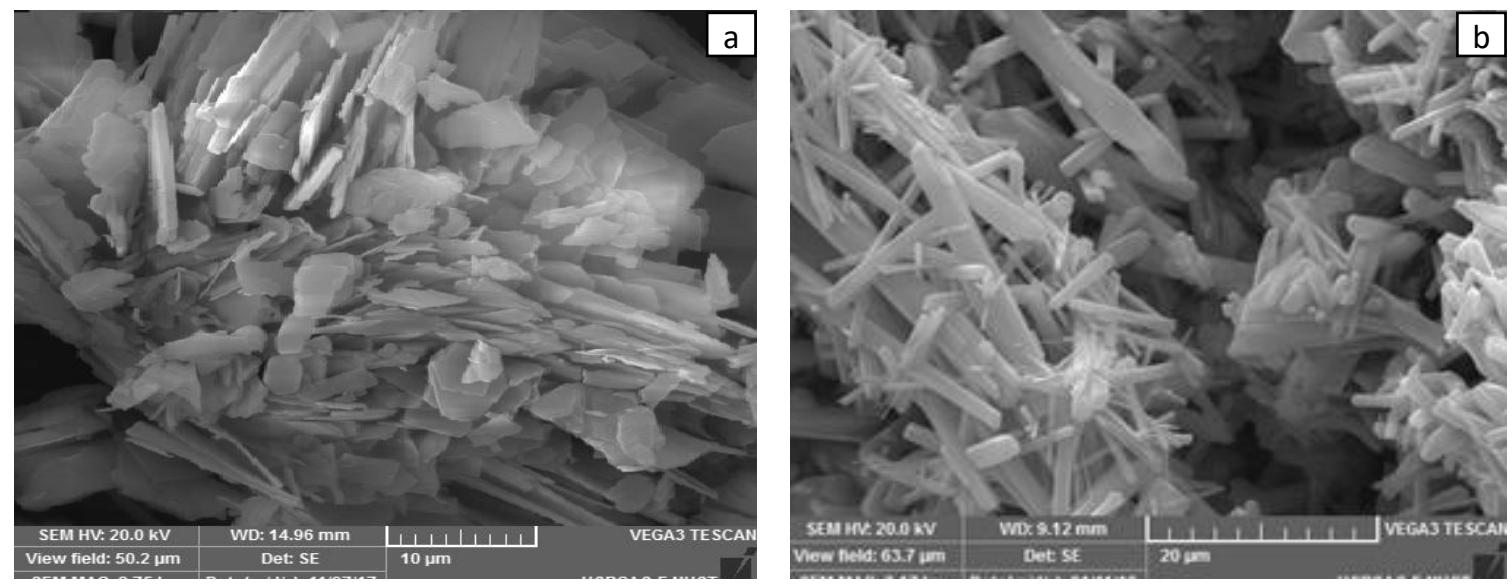

Figure 5. SEM images at $10 \mu \mathrm{m}$ for (a) Cu-BDC MOF and at $20 \mu \mathrm{m}$ for (b) Cu-BDC $\supset$ HMTA MOF. 


\section{6. $\mathrm{CO}_{2}$ Adsorption Studies of $\mathrm{Cu}$-BDC MOF and $\mathrm{Cu}$-BDC $\supset H M T A$}

The $\mathrm{CO}_{2}$ adsorption capacity for both MOF materials was evaluated by monitoring pseudo equilibrium adsorption uptake. Samples were initially degassed at $130{ }^{\circ} \mathrm{C}$ for $12 \mathrm{~h} .200 \mathrm{mg}$ of each sample was used for three consecutive adsorption-desorption cycles at $273 \mathrm{~K}$ or $298 \mathrm{~K}$ with adsorbate pressure ranging between 1 to 14 bar. For $\mathrm{Cu}$-BDC $\supset$ HMTA, the $\mathrm{CO}_{2}$ uptake recorded at 1 bar was $4.8 \mathrm{mmol} \mathrm{g}^{-1}(21.1 \mathrm{wt} \%)$, and $2.1 \mathrm{mmol} \mathrm{g}^{-1}(9.24 \mathrm{wt} \%)$ at $273 \mathrm{~K}$ and $298 \mathrm{~K}$, respectively (Figure 6). Notably, for $\mathrm{Cu}-\mathrm{BDC}$, without the amine modification, $\mathrm{CO}_{2}$ uptake was measured at 1 bar as only $1.2 \mathrm{mmol} \mathrm{g}^{-1}(5.28 \mathrm{wt} \%)$, and $0.8 \mathrm{mmol} \mathrm{g}^{-1}(3.53 \mathrm{wt} \%)$ at $273 \mathrm{~K}$ and $298 \mathrm{~K}$, respectively. At 14 bar, the $\mathrm{CO}_{2}$ uptake at $273^{\circ} \mathrm{C}$, and $298^{\circ} \mathrm{C}$ for $\mathrm{Cu}$-BDC $\supset$ HMTA is $12 \mathrm{mmol} \mathrm{g}^{-1}(52.8 \mathrm{wt} \%)$, and $9 \mathrm{mmol} \mathrm{g}^{-1}$ (39.6 wt \%), respectively (Figure 6), again markedly higher than for Cu-BDC (17.4 wt \%, and $13.2 \mathrm{wt} \%$ at $273 \mathrm{~K}$ and $298 \mathrm{~K}$, respectively).

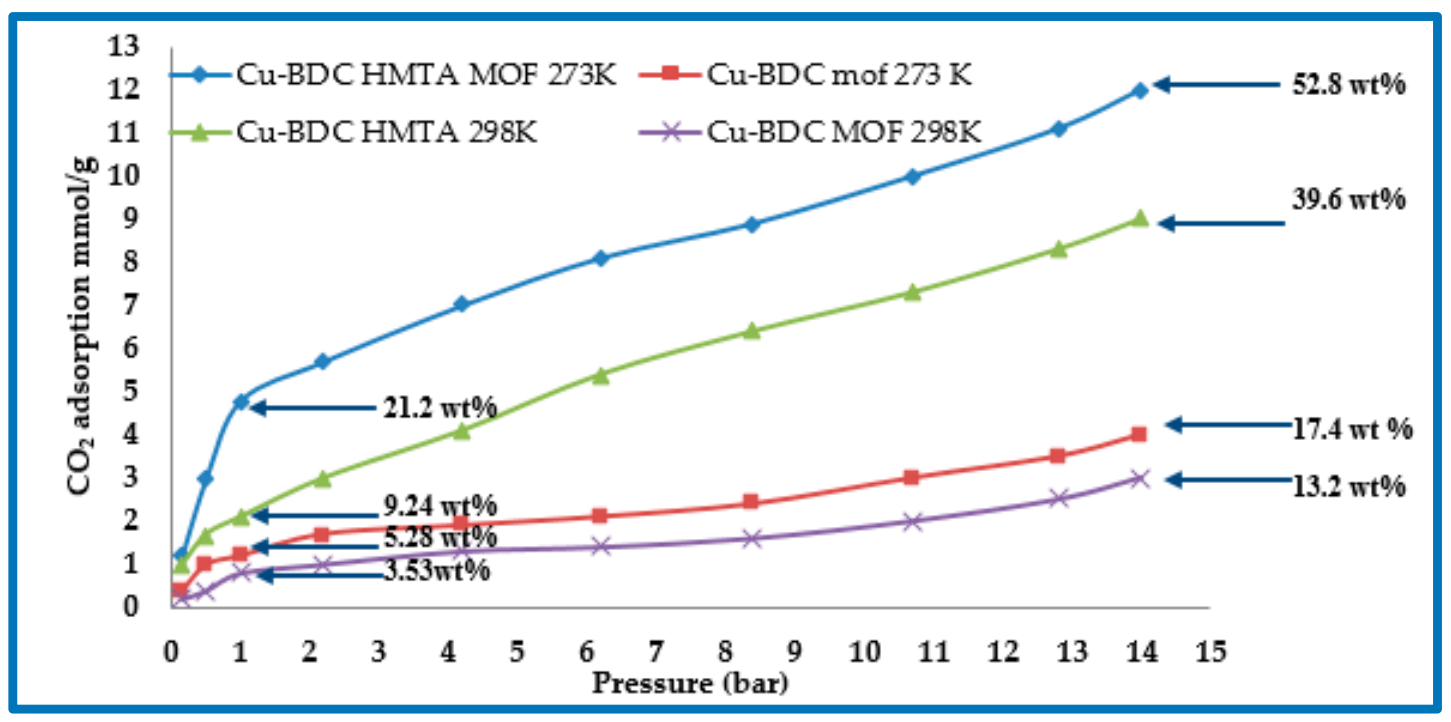

Figure 6. $\mathrm{CO}_{2}$ adsorption isotherms for $\mathrm{Cu}-\mathrm{BDC}$ and $\mathrm{Cu}-\mathrm{BDC} \supset \mathrm{HMTA}$ at $273 \mathrm{~K}$ and $298 \mathrm{~K}$, as shown.

\subsection{Surface Area and Porosity of $C u$-BDC $\supset H M T A M O F$}

The $\mathrm{N}_{2}$ adsorption isotherm for $\mathrm{Cu}$-BDC $\supset$ HMTA was recorded at $77 \mathrm{~K}$ (Figure 7B). The Langmuir and BET surface areas for Cu-BDC were found to be $868 \mathrm{~m}^{2} / \mathrm{g}$ and $708 \mathrm{~m}^{2} / \mathrm{g}$, respectively, while $\mathrm{Cu}-\mathrm{BDC} \supset$ HMTA revealed lower values of $683 \mathrm{~m}^{2} / \mathrm{g}$ (Langmuir), and $590 \mathrm{~m}^{2} / \mathrm{g}$ (BET) (Table 2). Although the introduction of the amine into Cu-BDC $\supset$ HMTA reduces its surface area, the $\mathrm{CO}_{2}$ adsorption is increased. The presence of additional binding sites in MOFs by amine/amide incorporation has been shown to induce dispersion, and electrostatic forces that enhance $\mathrm{CO}_{2}$ gas adsorption (Table 2) [13]. The isosteric heat of $\mathrm{CO}_{2}$ adsorption (Qst) in Cu-BDC $\supset$ HMTA was calculated from the adsorption isotherms at 273 and $298 \mathrm{~K}$ (Figure 7A) as $29.8 \mathrm{~kJ} \mathrm{~mol}^{-1}$. Such a moderate value is lower than many other MOFs (see Table 2), and is highly desirable because of the anticipated lower material regeneration energy demand.

Qst is the heat $Q$ released in a constant temperature calorimeter when a differential amount of gas is adsorbed at constant pressure. The Van't Hoff isobar equation relates Qst to adsorption isotherms at different temperatures. It is derived from equating the chemical potential of the adsorbed phase, and the gas phase, applying the Gibbs Helmholtz relation, and assuming that the vapor phase behaves like an ideal gas. From experimentally obtained isotherms at a constant amount adsorbed and two different temperatures $\left(T_{1}\right.$ and $\left.T_{2}\right)$, Qst is obtained by following equation:

$$
Q s t=R\left(\frac{(\ln P 1-\ln P 2)}{\left(\frac{1}{T 1}-\frac{1}{T 2}\right)}\right)
$$


where $\mathrm{R}$ is ideal gas constant. Isosteric heats of adsorption for $\mathrm{Cu}-\mathrm{BDC} \supset \mathrm{HMTA}$ were calculated using $273 \mathrm{~K}$ and $298 \mathrm{~K}$ isotherms using the slope of a Van't Hoff plot against the amount adsorbed. Here, the Qst value decreases with loading, indicating strong interaction between the quadrupole moment of carbon dioxide and the adsorbent surface.
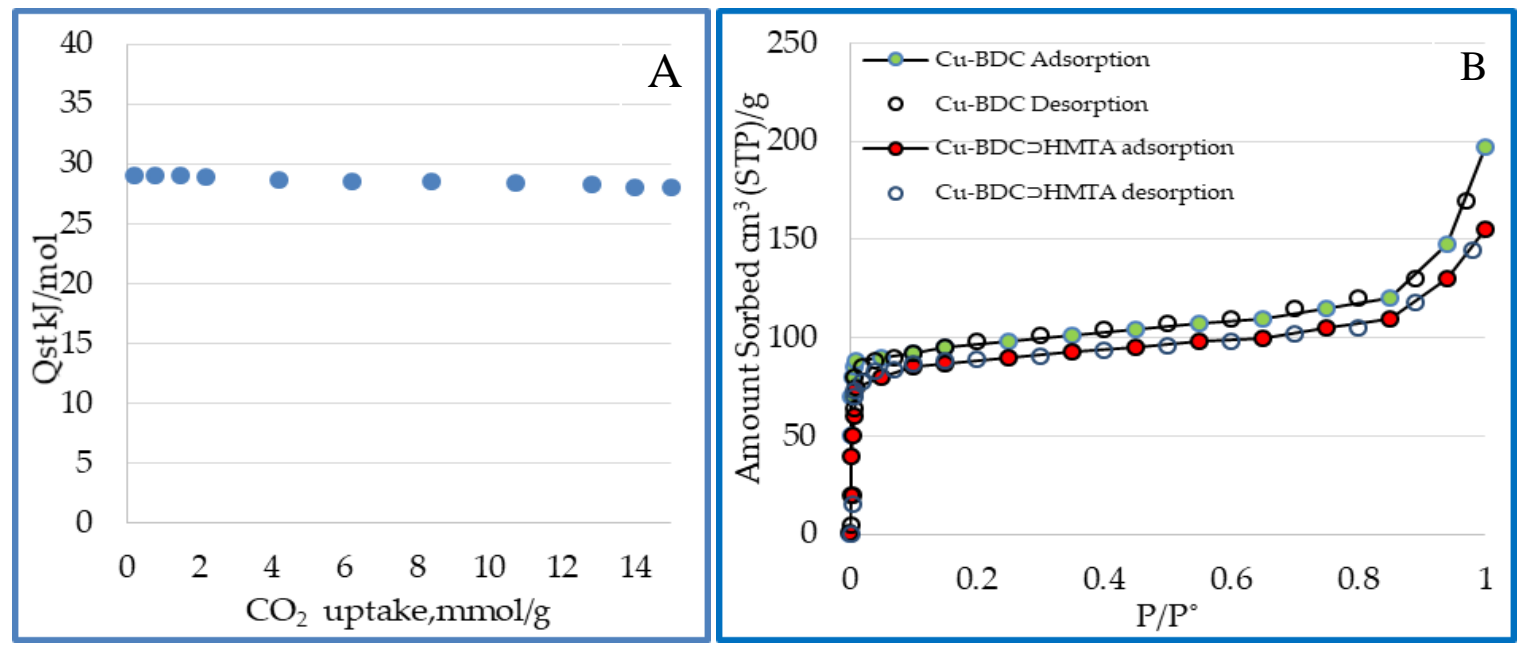

Figure 7. (A) Isosteric heats of $\mathrm{CO}_{2}$ adsorption onto Cu-BDCつHMTA. (B) $\mathrm{N}_{2}$ adsorption-desorption isotherms at $77 \mathrm{~K}$. Adsorption is represented by hollow circles (Red = Cu-BDCつHMTA, Green $=\mathrm{Cu}$ $\mathrm{BDC})$, and desorption is marked by closed circles.

Table 2. Surface area, $\mathrm{CO}_{2}$ uptake and Qst values for selected $\mathrm{Cu}$-based MOFs.

\begin{tabular}{|c|c|c|c|c|c|c|}
\hline Material & $\begin{array}{c}\text { BET } \\
\left(\mathrm{m}^{2} / \mathrm{g}\right)\end{array}$ & $\begin{array}{l}\text { Temperature } \\
\text { (K) }\end{array}$ & $\begin{array}{c}\text { Pressure } \\
\text { (bar) }\end{array}$ & $\begin{array}{c}\mathrm{CO}_{2} \text { Adsorption } \\
(\text { wt \%) }\end{array}$ & $\begin{array}{l}\text { Qst (KJ } \\
\text { mol-1) }^{-1}\end{array}$ & Reference \\
\hline $\mathrm{Cu}$ (TATB) & 3360 & 293 & - & - & 61 & [13] \\
\hline$\left[\mathrm{Cu}_{3}(\mathrm{TDPAT})\right]$ & 1938 & 273 & 1 & 25.8 & 42.2 & [14] \\
\hline $\mathrm{Cu}_{2}\left(\mathrm{H}_{2} \mathrm{O}\right)_{2} \mathrm{BDPO}$ & 2447 & 273 & 1 & 40.1 & 25.4 & [15] \\
\hline$\left[\mathrm{Cu}_{4}(\mu 4-\mathrm{O}) \mathrm{Cl}_{2}(\mathrm{COO})_{4} \mathrm{~N} 4\right]$ & 2690 & 273 & 10 & 27.3 & 36.5 & [16] \\
\hline $\mathrm{Cu}(\text { pia })_{2}\left(\mathrm{SiF}_{6}\right)(\mathrm{EtOH})_{2}\left(\mathrm{H}_{2} \mathrm{O}\right)_{12}$ & 285 & 296 & 1 & 5.5 & 30 & [17] \\
\hline$\left[\mathrm{Cu}_{3}(\mathrm{BTB})^{-6}\right]_{\mathrm{n}}$ & 3288 & 273 & 20 & 157 & - & [18] \\
\hline$\left[\mathrm{Cu}_{3} \mathrm{~L}_{2}\left(\mathrm{H}_{2} \mathrm{O}\right)_{5}\right]$ & 2690 & 273 & 1 & 27.3 & - & [19] \\
\hline$\left[\mathrm{Cu}_{2} \mathrm{PDAI}\left(\mathrm{H}_{2} \mathrm{O}\right)\right]$ & 1372 & 273 & 1 & 28.6 & 26.3 & [20] \\
\hline$\left[\mathrm{Cu}_{2}(\mathrm{TCMBT})(\mathrm{bpp})\left(\mu_{3}-\mathrm{OH}\right)\right] \cdot 6 \mathrm{H}_{2} \mathrm{O}$ & 808 & 298 & 20 & 25.5 & 26.7 & [21] \\
\hline$\left[\mathrm{Cu}_{2}\left(\mathrm{BDPT}^{4-}\right)\left(\mathrm{H}_{2} \mathrm{O}\right)_{2}\right]$ & 1400 & 273 & 1 & 30.7 & 22.5 & [22] \\
\hline en-CuBTTri & 345 & 298 & 1 & 58.2 & 90 & [23] \\
\hline en@CuBTC & - & 298 & 1 & 19.5 & 30 & [24] \\
\hline mmen-CuBTTri & 870 & 298 & 1 & 15.4 & - & [25] \\
\hline $\mathrm{Cu}-\mathrm{BDC}$ & 708 & 273 & $1(14)$ & $5.28(17.4)$ & - & Present study \\
\hline Cu-BDCつHMTA & 590 & 273 & $1(14)$ & $21.2(52.8)$ & 29.8 & Present study \\
\hline
\end{tabular}

The pore size distribution obtained from BET-BJH $\mathrm{N}_{2}$ adsorption shows micropores at around $8.3 \AA$ in $\mathrm{Cu}-\mathrm{BDC}$, and larger pores at $14 \AA$ that may originate from defects or inter-crystalline gaps [14]. Unsurprisingly, a narrow pore distribution of smaller pores around $7.1 \AA$ is observed in the Cu-BDCつHMTA sample.

The uptake of $\mathrm{CO}_{2}$ is only part of the utility of these materials. They also need to have reproducible uptake on more than one sorption-desorption cycle. $\mathrm{Cu}$-BDC revealed a significant loss in adsorption capacity over successive operations compared to Cu-BDC $\supset$ HMTA (Figure 8). Here, adsorption capacity calculated at $298 \mathrm{~K}$ and 14 bar for Cu-BDC lowered by about $14 \%$ after three cycles from 3 to $2.6 \mathrm{mmol} / \mathrm{g}$. 
This decrease in adsorption capacity over successive cycles was more prominent at higher temperature compared to lower temperature (273 K) adsorption. In contrast, Cu-BDC $\supset$ HMTA demonstrated much lower percentage decline in $\mathrm{CO}_{2}$ uptake over three successive adsorption cycles $(1.1 \%$ at $298 \mathrm{~K}$ and $0.83 \%$ at $273 \mathrm{~K})$.

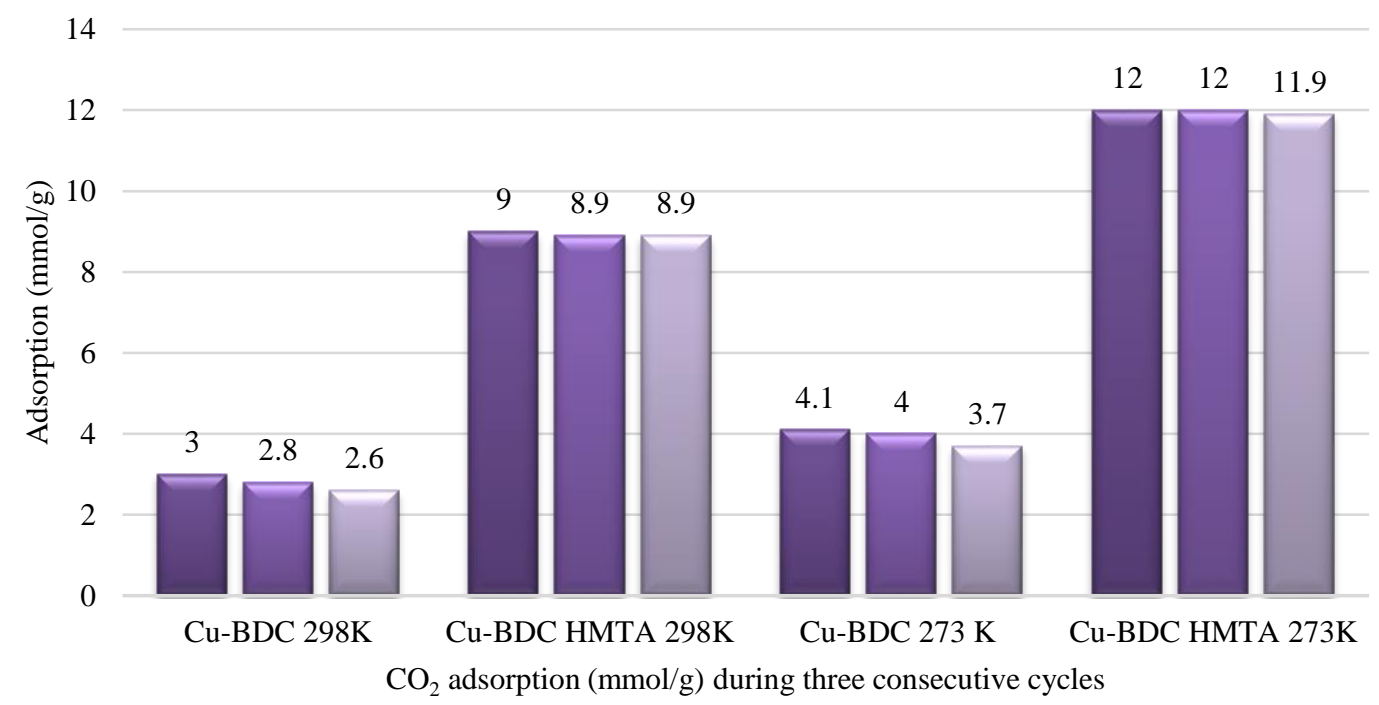

Figure 8. $\mathrm{CO}_{2}$ adsorption in mmol/g calculated at 14 bar for $\mathrm{Cu}-\mathrm{BDC}$ and $\mathrm{Cu}-\mathrm{BDC} \supset$ HMTA at $273 \mathrm{~K}$ and $298 \mathrm{~K}$ as shown.

\section{Conclusions}

In summary, we report the simple modification of a Cu-BDC MOF during synthesis by the incorporation of a hexamethylenetetramine additive. The Cu-BDC $\supset$ HMTA MOF material forms as a crystalline solid with rod-like crystallites. Thermogravimetric studies reveal that Cu-BDCつHMTA is more thermally stable than Cu-BDC MOF. Moreover, carbon dioxide adsorption studies for these samples reveal markedly better carbon dioxide uptake by the amine-modified framework $(5.25 \mathrm{wt} \%$ for $\mathrm{Cu}-\mathrm{BDC}$, and $21.2 \mathrm{wt} \%$ for $\mathrm{Cu}-\mathrm{BDC} \supset \mathrm{HMTA}$, respectively, at $273 \mathrm{~K}$ and $1 \mathrm{bar}$ ). The addition of nitrogen atoms by the incorporation of HMTA leads to the enhanced adsorption of $\mathrm{CO}_{2}$ gas, which we ascribe to favorable interactions [26] between $\mathrm{CO}_{2}$ molecules and the nitrogen-modified pores [27]. The modified MOF, Cu-BDCつHMTA, also displays enhanced cyclic stability and can be reused over three cycles. This study describes a cost-effective strategy for the incorporation of amine groups in MOF structures, for enhanced $\mathrm{CO}_{2}$ capture applications, using HMTA as a cheap additive. This serves as a low-cost alternative to expensive amine based ligands that are often custom-built to make MOFs for carbon dioxide capture. Future studies are needed to address the longer-term stability of Cu-BDC $\supset$ HMTA and stability to contaminants.

Author Contributions: Conceptualization, T.L.E.; Data curation, M.A.; Investigation, A.A.; Methodology, N.I.; Supervision, T.N., T.L.E.; writing, all authors.

Funding: Funding for this project was provided by USPCAS-E, Cardiff University, NUST Pakistan and Higher Education, Pakistan and The APC was funded by NUST, Pakistan.

Acknowledgments: The authors are very grateful to Higher Education Commission, Pakistan for providing financial support to carry out some part of this research work at Cardiff University, UK. TLE gratefully acknowledges the Royal Society for the award of a University Research Fellowship (6866), and Cardiff University for funding.

Conflicts of Interest: The authors declare no conflict of interest. 


\section{References}

1. Bao, Z.; Yu, L.; Ren, Q.; Lu, X.; Deng, S. Adsorption of $\mathrm{CO}_{2}$ and $\mathrm{CH}_{4}$ on a magnesium-based metal organic framework. J. Colloid Interface Sci. 2011, 353, 549-556. [CrossRef] [PubMed]

2. Liu, J.; Thallapally, P.K.; McGrail, B.P.; Brown, D.R.; Liu, J. Progress in adsorption-based $\mathrm{CO}_{2}$ capture by metal-organic frameworks. Chem. Soc. Rev. 2012, 41, 2308-2322. [CrossRef] [PubMed]

3. Sumida, K.; Rogow, D.L.; Mason, J.A.; McDonald, T.M.; Bloch, E.D.; Herm, Z.R.; Bae, T.-H.; Long, J.R. Carbon Dioxide Capture in Metal-Organic Frameworks. Chem. Rev. 2012, 112, 724-781. [CrossRef] [PubMed]

4. Easun, T.L.; Nevin, A.N. Metal nodes and metal sites in metal-organic frameworks. Organomet. Chem. 2019, 42, 54-79.

5. Li, J.R.; Sculley, J.; Zhou, H.C. Metal-Organic Frameworks for Separations. Chem. Rev. 2012, 112, 869-932. [CrossRef] [PubMed]

6. Han, D.; Jiang, F.L.; Wu, M.Y.; Chen, L.; Chen, Q.H.; Hong, M.C. A non-interpenetrated porous metal-organic framework with high gas-uptake capacity. Chem. Commun. 2011, 47, 9861-9866. [CrossRef]

7. Furukawa, H.; Cordova, K.E.; O'Keeffe, M.; Yaghi, O.M. The chemistry and applications of metal-organic frameworks. Science 2013, 341, 1230444. [CrossRef] [PubMed]

8. Furukawa, H.; Muller, U.; Yaghi, O.M. "Heterogeneity within order" in metal-organic frameworks. Angew. Chem. Int. Ed. 2015, 54, 3417-3430. [CrossRef]

9. Mason, J.A.; McDonald, T.M.; Bae, T.-H.; Bachman, J.E.; Sumida, K.; Dutton, J.J.; Kaye, S.S.; Long, J.R. Application of a high-throughput analyzer in evaluating solid adsorbents for post combustion carbon capture via multicomponent adsorption of $\mathrm{CO}_{2}, \mathrm{~N}_{2}$, and $\mathrm{H}_{2}$ O. J. Am. Chem. Soc. 2015, 137, 4787-4803. [CrossRef]

10. Carson, C.G.; Hardcastle, K.; Schwartz, J.; Liu, X.; Hoffmann, C.; Gerhardt, R.A.; Tannenbaum, R. Synthesis and structure characterization of copper terephthalate metal-organic frameworks. Eur. J. Inorg. Chem. 2009, 16, 2338-2343. [CrossRef]

11. Hexamethylenetetraamine; Sigma-Aldrich Corporation online (UK) pricing 11th April 2019 of $£ 62.80$ for 4 kg, ReagentPlus@, 99\%. Available online: https://www.sigmaaldrich.com/catalog/product/sial/h11300? lang=en\&region=PK (accessed on 28 April 2019).

12. Ilyes, E.; Florea, M.; Madalan, A.M.; Haiduc, I.; Parvulescu, V.I.; Andruh, M. A Robust Metal-Organic Framework Constructed from Alkoxo-Bridged Binuclear Nodes and Hexamethylenetetramine Spacers: Crystal Structure and Sorption Studies. Inorg. Chem. 2012, 51, 7954-7956. [CrossRef] [PubMed]

13. Caskey, S.R.; Wong-Foy, A.G.; Matzger, A.J. Dramatic tuning of carbon dioxide uptake via metal substitution in a coordination polymer with cylindrical pores. J. Am. Chem. Soc. 2008, 130, 10870-10871. [CrossRef]

14. Yang, Y.; Lin, R.; Ge, L.; Hou, L.; Bernhardt, P.; Rufford, T.E.; Wang, S.; Rudolph, V.; Wang, Y.; Zhu, Z. Synthesis and characterization of three amino-functionalized metal-organic frameworks based on the 2-aminoterephthalic ligand. Dalton Trans. 2015, 44, 8190-8197. [CrossRef]

15. Hu, Z.; Nalaparaju, A.; Peng, Y.; Jiang, J.; Zhao, D. Modulated hydrothermal synthesis of UIO-66(Hf) type Metal Organic Frameworks for Optimal Carbon Dioxide Separation. Inorg. Chem. 2016, 55, 1134-1141. [CrossRef] [PubMed]

16. Zheng, B.; Bai, J.; Duan, J.; Wojtas, L.; Zaworotko, M.J. Enhanced $\mathrm{CO}_{2}$ Binding Affinity of a High-Uptakerht-Type Metal-Organic Framework Decorated with Acylamide Groups. J. Am. Chem. Soc. 2011, 133, 748-751. [CrossRef] [PubMed]

17. Cai, J.F.; Wang, H.Z.; Wang, H.L.; Duan, X.; Wang, Z.Y.; Cui, Y.J.; Yang, Y.; Chen, B.L.; Qian, G.D. An amino-decorated $\mathrm{NbO}$-type metal-organic framework for high $\mathrm{C}_{2} \mathrm{H}_{2}$ storage and selective $\mathrm{CO}_{2}$ capture. RSC Adv. 2015, 5, 77417-77422.

18. Xiong, S.; He, Y.; Krishna, R.; Chen, B.; Wang, Z. Metal-Organic Framework With Functional Amide Groups For Highly Selective Gas Separation. Cryst. Growth Des. 2013, 13, 2670-2674. [CrossRef]

19. Zheng, B.; Yang, Z.; Bai, J.; Li, Y.; Li, S. High and selective $\mathrm{CO}_{2}$ capture by two mesoporous acylamide-functionalized rht-type metal-organic frameworks. Chem. Commun. 2012, 48, 7025-7028. [CrossRef]

20. Duan, J.; Yang, Z.; Bai, J.; Zheng, B.; Li, Y.; Li, S. Highly selective $\mathrm{CO}_{2}$ capture of an agw-type metal-organic framework with inserted amides: Experimental and theoretical studies. Chem. Commun. 2012, 48, 3058-3060. [CrossRef] 
21. Park, J.; Li, J.R.; Chen, Y.P.; Yu, J.; Yakovenko, A.; Wang, Z.U.; Sun, L.B.; Balbuena, P.B.; Zhou, H.C. A Versatile Metal-Organic Framework For Carbon Dioxide Capture and Cooperative Catalysis. Chem. Commun. 2012, 48, 9995-9997. [CrossRef]

22. Lu, Z.; Xing, H.; Sun, R.; Bai, J.; Zheng, B.; Li, Y. Water Stable Metal-Organic Framework Evolutionally Formed from a Flexible Multidentate Ligand with Acylamide Groups for Selective $\mathrm{CO}_{2}$ Adsorption. Cryst. Growth Des. 2012, 12, 1081-1084. [CrossRef]

23. Wang, Z.; Zheng, B.; Liu, H.; Lin, X.; Yu, X.; Yi, P.; Yun, R. High Capacity Gas Storage by a Microporous Oxalamide Functionalized NbO-Type Metal-Organic Framework. Cryst. Growth Des. 2013, 13, 5001-5006. [CrossRef]

24. Demessence, A.; D'Alessandro, D.M.; Foo, M.L.; Long, J.R. Strong $\mathrm{CO}_{2}$ binding in a water stable, triazolate-bridged metal-organic framework functionalized with ethylenediamine. J. Am. Chem. Soc. 2009, 131, 8784-8786. [CrossRef] [PubMed]

25. Montoro, C.; Garcia, E.; Calero, S.; Perez-Fernandez, M.A.; Lopez, A.L.; Barea, E.; Navarro, J. Functionalization of MOF open metal sites with pendant amines for $\mathrm{CO}_{2}$ capture. J. Mater. Chem. 2012, 22, 10155-10158. [CrossRef]

26. McDonald, T.M.; D'Alessandro, D.M.; Krishna, R.; Long, J.R. Enhanced carbon dioxide capture upon incorporation of $\mathrm{N}, \mathrm{N}^{\prime}$-dimethylethylenediamine in the metal-organic framework CuBTTri. Chem. Sci. 2011, 2, 2022-2028. [CrossRef]

27. Karmakar, A.; Desai, A.V.; Manna, B.; Joarder, B.; Ghosh, S.K. An Amide-Functionalized Dynamic Metal-Organic Framework Exhibiting Visual Colorimetric Anion Exchange and Selective Uptake of Benzene over Cyclohexane. Chem. A Eur. J. 2015, 21, 7071-7076. [CrossRef] [PubMed]

(C) 2019 by the authors. Licensee MDPI, Basel, Switzerland. This article is an open access article distributed under the terms and conditions of the Creative Commons Attribution (CC BY) license (http://creativecommons.org/licenses/by/4.0/). 